\title{
RISK REDUCTION IN TRANSPORT SYSTEM IN EMERGENCY CONDITIONS: A FRAMEWORK FOR DECISION SUPPORT SYSTEMS
}

\author{
MASSIMO DI GANGI \& ORLANDO MARCO BELCORE \\ Dipartimento di Ingegneria, Università degli Studi di Messina, Italy
}

\begin{abstract}
Risk analysis and assessment allow analysts and decision-makers to measure whether the losses (economic and human lives) are tolerable and define appropriate actions. Moreover, planning tools and models applied to the emergency decision management (EDM) and spatial decision support system (SDSS) improve the collective interest in increasing the resilience for societal risks. Starting from recent improvements offered by the liberalisation for the GPS data and open data services, this paper aims to suggest an architecture for an open data Web SDSS framework. Furthermore, it integrates into its modular structure the possibility to analyse both networks and evacuees behaviours through the integration of the transportation system model (TSM) models with geographical information systems (GIS), information technology systems (ITS) and volunteered geographic information (VGI). The main advantage of such a system is coping with incoming and in-progress emergencies, utilising on-time data, connecting multiple databases and sources of information, and implementing a participatory process involving different stakeholders.
\end{abstract}

Keywords: decision support system, evacuation modelling, emergency management, GIS.

\section{INTRODUCTION}

The interest in Emergency Decision Managment (EDM) is a key issue in emergency management; it aims to increase the collective interest upon the need to increase the resilience for social risks.

Many researchers and stakeholders approached the problem by focusing on "risk analysis and assessment" as an indicator of managing emergency conditions [1]-[3]. Depending on the nature of the event, evacuation represents the instrument to limit the factor of risk exposure, as well as logistics operations (placing inventory management, rescue vehicles and teams) increase both response and recovery phases. The former approach will be of primary interest in this discussion, and therefore the following considerations will focus more on modelling and intervention strategies to limit exposure and reduce the risk factor. The present work is part of a collection of papers upon risk reduction in transport systems during emergency, the same are listed below:

- Risk reduction in transport system in emergency conditions: A framework for network design problem;

- Risk reduction in transport system in emergency conditions: A framework for demand analysis;

- Risk reduction in transport system in emergency conditions: A framework for supply analysis;

- Risk reduction in transport system in emergency conditions: A framework for evacuation planning.

The project represents a step forward respect to previous analyses conducted in Di Gangi [4], Russo and Vitetta [5] and Russo and Rindone [6], where authors focused on: 
- calibrating, validating and test models and procedures to assess the effects of action to reduce risk in terms of exposure;

- constructing a prototype laboratory system of models;

- providing public administration with guidelines for planning and managing evacuation.

Main goal of the present consists in adapting planning emergency tools and models to the novelty given by communication, geographical information systems (GIS) based technology and information technology systems (ITS) and introduce the proposal for the creation of a new spatial decision support system (SDSS) framework. In Section 2, question marks at the basis of the research recovery increasing by social knowledge (RISK) are provided; in Section 3 it is described current knowledge on the theme; Section 4 is dedicated to some considerations and the proposal for a web decision support systems (DSS), focused on GIS; ITS technology, GIS and mobile tools, whose main feature will consist into the possibility to involve citizens as an active agent into evacuation process and obtain real-time information to help decision-makers.

\section{RISK ASSESSMENT}

Planning of a system for emergency conditions starts from a risk assessment (R) analysis in different disaster scenarios, from which it is possible to estimate the extent of damage and the number of victims. Risk assessment aims to identify and to analyse risks and understand the priorities for intervention in order to elaborate strategic actions to contain or mitigate them.

Since the last decade of the twentieth century, risk has been defined in international literature as the "undesirable consequence of a particular activity in relation to the probability of its occurrence" and conventionally expressed using a compact formulation.

$$
R=P \cdot M
$$

where $P$ is the probability of occurrence; $M$ is the magnitude, which represents the extent of the consequences. The magnitude $M$ can be further segmented into two elements:

$$
M=V \cdot E,
$$

where $V$ is the vulnerability of the system, or the inability of the single element, or parts, of the system, to resist the event; $\mathrm{E}$ is the exposure of people and goods present in the system. The synthetic formulation of risk can be expressed as

$$
R=P \cdot V \cdot E,
$$

where each of its components may be characterised using both spatial and temporal variables. According to the nature of the event, in order to reduce the risk factor (see Fig. 1), it's possible ti implement different measures such as:

- prevention measures to reduce probability;

- protection measures to reduce magnitude, which can consist of a reduction of both vulnerability and exposure.

Nevertheless, the reduction of $\mathrm{P}$ is limited (in terms of probability) to some kind of manmade events (power failure, radiation leak, hazardous freight, etc.), whereas it results difficult on natural disasters. Besides, it is always possible to work on risk exposure and its factors; it represents the value of people, goods and land use at a specific point in time and space that might be affected during and after an event. According to the risk formulation, it is 


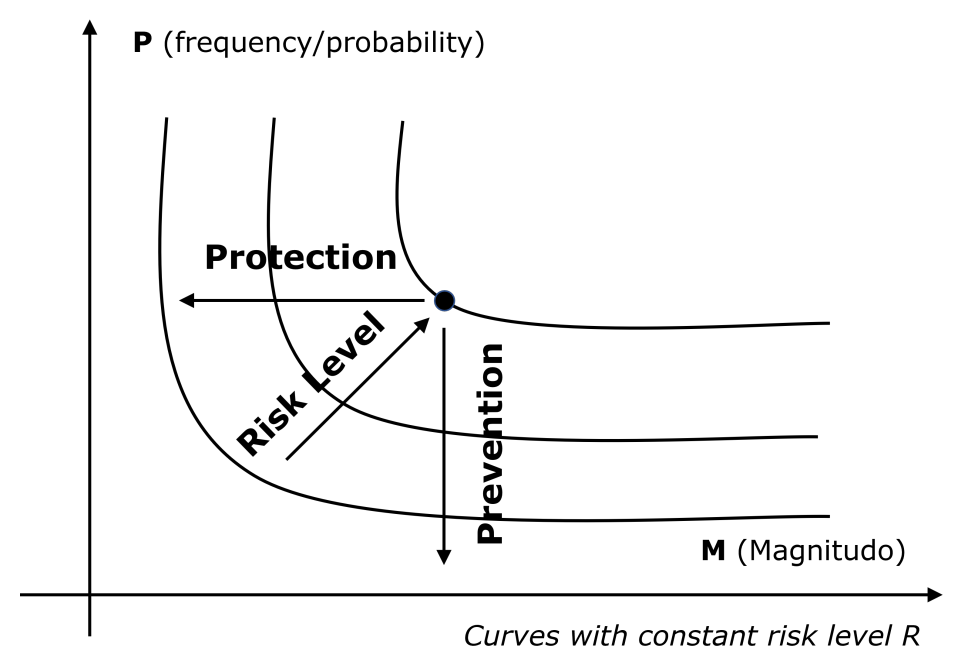

Figure 1: Possible measure for the social risk reduction [7].

important also to share between the individual level and the more interesting cardinal measure of social/societal risk whose formulation depends on $R: f(x, y, t)$.

Previous assumptions let the analyst focus also on important factors and resume a further classification of risk such [7]:

- the cause of the event, which can be natural (i.e. seismic, hydro-geological, volcanic, ...) or anthropic (i.e. accident with dangerous goods, nuclear event, ... );

- the spatial effect: punctual or diffuse;

- the temporal effect (impact), which can be immediate or delayed (each risk component may be associated to a reference period, which ranges from some years to few seconds);

- the effect on the transport system, which can be on the demand, network and demand - network interaction components.

For this reason, at the basis of our work we have to fix some clues and questions that will be part of our proposal:

- How can the risk be reduced by employing urban evacuation;

- How can transport system models may support operations;

- How transportation system model (TSM) interact with ITS during emergency;

- How can public administrations organise a decision support system to address an increasing recovery;

- How can citizens become a key part of the overall process;

- How to provide to evacuees the best social knowledge about safe destinations and routes;

to answer to the previous questions the proposal of a new framework will be introduced.

\section{STATE OF THE ART}

As stated before, the evacuation measures can be directly connected with recovery for a system, this implies how the risk reduction represents the basis for a resilient system, and the set of measures to implement is the result of a planning process. 
Evacuation procedures and planning are defined according to the product-plans dimensions and interactions between the subjects involved. In Italy, the emergency planning process is governed by Law n. 225/92, which defines the Italian Civil Protection Service's competence in case of emergency conditions. At the different territorial scales (national, regional and local), the law identifies different public actors responsible for planning and program solutions to face emergencies. After introducing administrative decentralisation (Law n. 59/97, Legislative Decree n. 112/98), the Italian Regions and local authorities gained a central role in civil protection.

Nowadays, the legislation does not request the application of quantitative methods to verify evacuation procedures inside the local plans, and this lack in the law offers the researchers an opportunity. Indeed, the evaluation of risk index and safety conditions goes through a careful analysis of the performances that this can guarantee. From the mathematical point of view, the simulation of a system and the management of flows (goods, vehicles, and resources) correspond to the resolution of the canonical four-stage model (emission, destination, modal and route choice) and as highlighted in Fig. 2. The approach to be followed is strongly conditioned by the event, the effects that it can trigger on the transport systems, and the interactions among the different activities that persist in the area. Many authors dealt with emergency conditions both in the preventive and post-catastrophe phases [9] and following the principle of evacuation planning (EP) some guides have been drawn up such as the more generic cases developed by Russo and Rindone [6], [10] or more specific formulations as seen in Wei et al. [11] and Chen et al. [12], such as the tools for the mobilization of emergency teams [13] or even case studies for planning or verifying the evacuation of areas subject to disasters [14] $-[16]$.

\subsection{Planning an evacuation model}

Thus, drawing up a study for an evacuation requires a complete survey on infrastructures, land use and the generation of scenarios for supply e demand and assignment interaction. As an output, the analyst obtains the exposure evaluation associated with flows and link performance. In Fig. 3 a generic evacuation plane framework is reported. The last step in the previous procedure involves risk acceptance and exposure as a direct consequence of the assignment analysis. The evaluated formulation can be used as an indicator whose threshold value may represent the success to reduce risk factors connected with emergency situations. As a matter of fact, Russo and Rindone [6] presented a planning tool for reducing the consequences of an emergency, the same was also calibrated and validated through onfield experimentation for a real case evacuation in a small town in Southern Italy. The output consisted in a multi-stage demand models calibration for the different user classes.

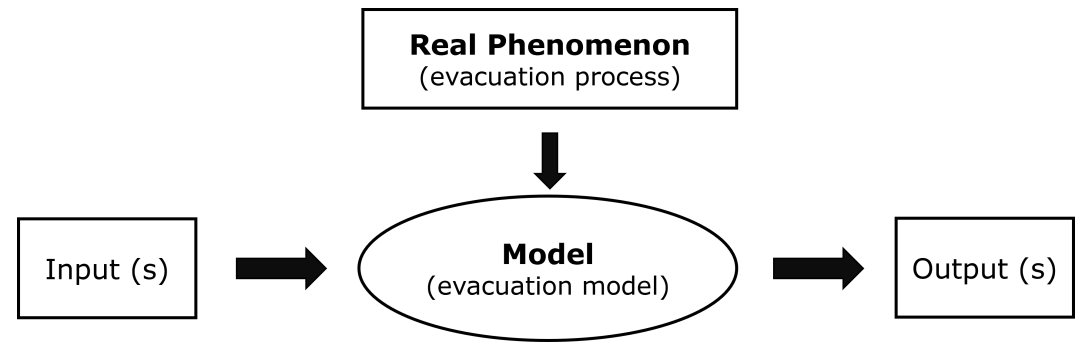

Figure 2: Generic evacuation modelling process [8]. 


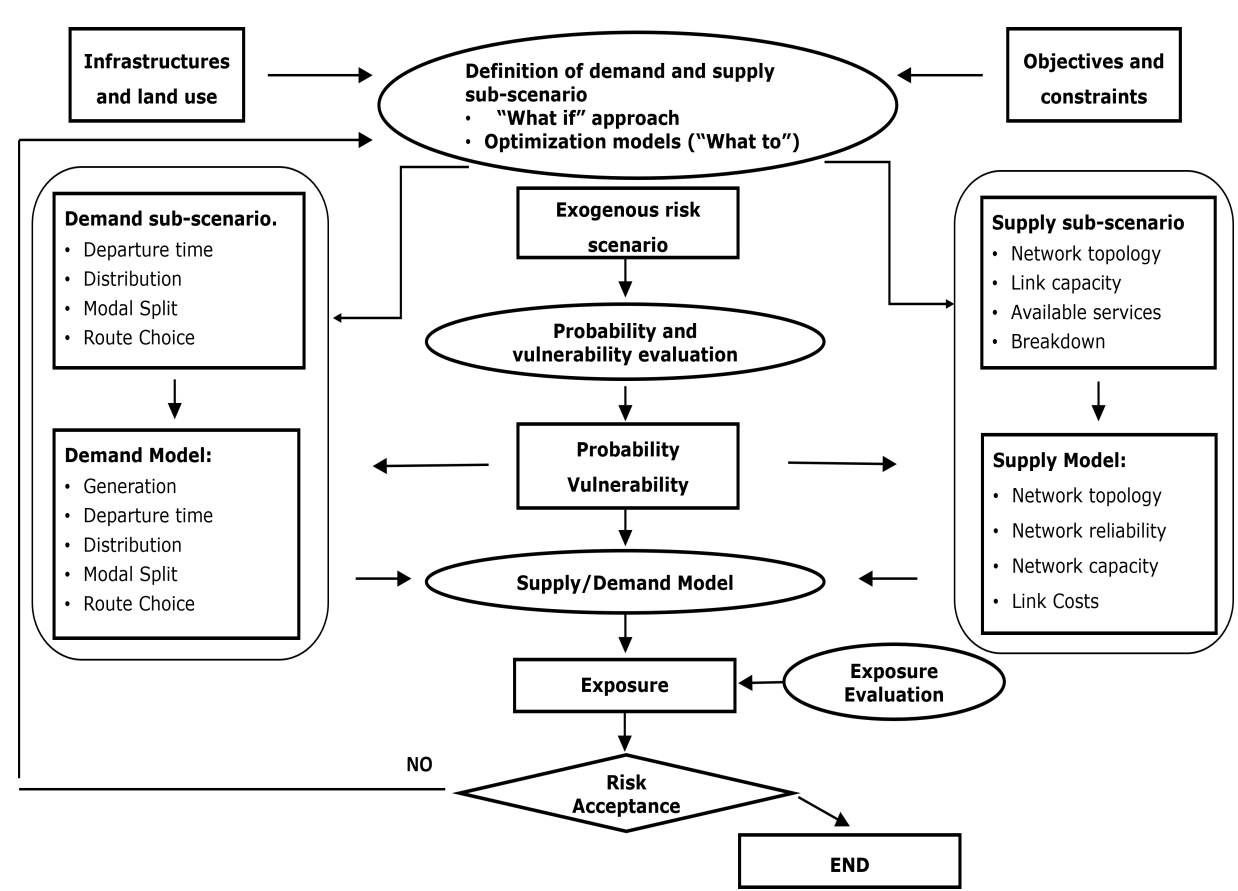

Figure 3: The procedure for a generic evacuation plan [5].

Urban evacuation studies have been carried out using methodologies based on TSM, and TSM simulate a transport system through a process based on the interaction between demand and supply system in terms of cost formulation (disutilities) and flows. Thus, the network model simulates performance and flows, the travel demand model simulates users' choices, the interaction between these to model is operated through assignment employing static (static traffic assignment (STA)) or dynamic interaction (dynamic traffic assignment (DTA)). The former simulates the transport system in stationary conditions, whereas DTA allows time evolution and progress. For a comprehensive review on existing DSS and their capability, the reader is suggested to read Vitetta et al. [17]. In general, exists various traffic assignment simulation tools on the market whose main limitation involves calibration and validation due to the complex behaviours to simulate [18]-[20].

Demand model for evacuation, when an exogenous event occurs to affect the system, have received little attention and classical algorithms do not cope with extraordinary conditions related to the event itself, one of the rare exceptions in this field is represented by Russo and Chilà [21]. In it authors proposed the resolution for the demand problem under emergency conditions, using real experimentation data from a small case study. As demonstrated by Russo and Chilà [22] demand models usually do not take into account information as an influencing factor on evacuees' behaviour, the authors reviewed some of the main important existing demand models and highlighted how only some could be capable of being adapted to emergency conditions and simulate evacuations, and as a consequence of this in the last three decades authors approached the problem mainly focusing on clear time evaluation, critical infrastructure and, the vulnerability of the network.

As a matter of fact when an exogenous event occurs users are not informed about congestion or network reliability, and since now TSM are based on two general conditions:(i) 
each person knows what to do; (ii) each person follows pre-order instructions; anyway in a real situation, furthermore during an emergency, this is not always true.

Usually, simulations are carried out employing different hypotheses on the characteristics of the flows and observed variables. Thus we share macroscopic with continuous flow representation and aggregate variables [23]; mesocopic, such as in Di Gangi and Velonà [24] where evacuees behaviours is represented by groups and their characteristics, as well as in micro-simulation that let the analyst to evaluate specifics characteristics about the evacuees intentions and reactions according to their profile [25], [26]. Concerning their nature, the macro model is adequate for application to extended areas where major needs consist of a relatively rapid execution and a scarce data granularity as input. Whereas mesoscopic and microscopic needs more data and their specification can benefit from the new opportunity offered by volunteered geographic information (VGI), satellite systems, long and short-range sensors, and the opportunity to implement variable messages and signal optimisation, as well as floating car data and in general all the information available from ITS function present along with the network. As demonstrated in Vitetta et al. [17] obtained data from direct observation are the basis of the calibration of a microscopic link model, as a response of the evacuees' choices, through the evaluation of performance indicators (total distance on the network, total travel time, average travel time and speed) and performance evolution indicators such as a number of vehicles on the network and number of the vehicles that reach the safe area. In further work, Vitetta et al. [27] underlined the importance of the use of TSM, to simulate classical one to one and many to one problems, and evacuation operation to organise evacuation for weak users and preserve their life. To achieve a better understanding a real-time monitoring is essential. The use of different data sources, real-time information and evacuees behaviour still today represents a novel proposal whose final objective will consist in reducing the existing gap between user optimum equilibrium and general optimum for the system. Furthermore, a real-time and mobile SDSS adoption will get the possibility to directly involve citizens as a source also. The continuous data stream in association with real-time simulation can provide enhanced situational awareness and dynamic feedback.

The opportunity to monitor evacuees using mobile and information and communication technology (ICT) infrastructure is an essential tool for the introduction of a new generation of collaborative SDSS. Gwynne et al. [28] the authors provided state of the art at the turn of the 1980s and 1990s, and it emerged how the models could not ignore a behavioural approach, and researchers should focus on the behaviour of displaced people who can deviate far from the mathematical approximations underlying the models as the same as in Vorst [29] where the author focused its work on user behaviour, highlighting how the psychological parameters, too often not evaluated, play a decisive role in understanding and therefore simulating evacuees' behaviour. Anyway many authors tried to give back a better understanding about people choices using different approaches to the problems and some of the most representative examples are offered by the use of rules and physicalmathematical approximations [30], the use of artificial intelligence models [31], probabilistic simulations [16] or agent models [8], [32], [33].

The importance of the commitment of ITS systems as tools for real-time monitoring of the effects produced, on networks, of evacuation and the impact of decisions taken by analysts and displaced persons is reiterated in Chilà et al. [34]. It represents an overview of a methodology that could be applied to emergency conditions integrated with ITS, and authors propose a general methodology to implement ITS into DSS. In it, thanks to the output from a small case study, models are calibrated and validated.

Finally, a frontier of great interest for research and public administrations lies in the possibility of integrating, in a single database, various sources of real-time data using sensors 
and short and long-range communications as well as alert and monitoring systems that are prepared by both central and international protocols as well as spontaneous user reports [32], [35]-[37].

\subsection{Review on developed DSS framework approaches}

We have further focused our review over the progress and intuitions from the academics ad practitioners during the last 40 years and emerged how the frameworks of the DSS moved from an analytical approach based on operative research (OR) dynamics and resolution based on scenario hypothesis and simulation to a more flexible and comprehensive use of GIS information and spatial analysis. Furthermore, in the last twenty years, the liberalisation of data and the progress in open data availability improved the possibility to develop SDSS and group decision support system (GDSS) through the employment of different decision-makers and a wider data source to elaborate solution [38].

Nowadays academics focuses on the development of SDSS whose essential elements are:

- a database capable of managing geo-referenced data;

- an interactive database capable to communicate with users, sensors and decision makers in real time;

- a mathematical model that simulates decision-making processes;

- a graphical interface that assists both the user and the decision maker.

- the opportunity to integrate multi criteria analyses and evaluate different layers of information;

This overview explicitly introduces the general objective at the basis of a SDSS for the simulation of a TSM as an instrument to support evacuation planning.

The literary review shed in light how only a few of the developed DSS nowadays integrate into their routine real evacuees' choices in real-time, follow the evolution of the event itself, and the collapse of arterial and bottlenecks, to do this the analyst has to estimate indicators, identify key parameters and cross-refer them with other databases like GIS or satellite, and implement ITS thanks to smart roads projects and VGI.

Most of them are evaluated for specific case study and emergencies, usually do not integrate dynamic assignment and micro simulation effects. The liberalisation of GPS data and geo-information, allowed faster progress on DSS workflow and the technologies supported by Web and Mobile, which now represent one of the frontiers to be explored [39] by integrating methodologies that support the use of Artificial Intelligence or interactive graphic interfaces, to evaluate different scenario effects employing geoprocessing tools and geocomputerized systems [38], [40]. The introduction of GIS information system let the analyst to evaluate qualitative and quantitative effects at the same time through the use of simulations. For a more in-depth discussion on GIS-based DSS, the reader is referred to Russo and Chilà [41], and as demonstrated by Zhou et al. [42], the interest of researchers focused on EDM that have at their basis make use of GIS to combine mathematical models and qualitative data offered by the geo-information and ICT, this parallel use of database and knowledge engine let the analysts to reduce the risks connected with the evolution of the event itself and some authors developed recently some example exploring the opportunities offered by the before mentioned coupling [43]-[45]. In Wei et al. [11], Zheng et al. [46], Zhu et al. [47], and Olyazadeh et al. [48] we found some proposal of generic architectures for the construction of a GIS-based DSS. The authors all agree to suggest modularity as a source of integration to enlarge the field of application and the possibility to combine different professions and the integration of open-data sources to enlarge the amount of information and 
to proceed to a universal standard to aggregate it in order to help the public administration to collect it with with a limited amount of money.

\section{PROPOSAL FOR A MOBILE SDSS}

So far, we focused our synopsis on the DSS focusing on the architecture to be associated with it and the simulation processes carried out by the analysis sub-models. It has been evident that many of the models developed so far have a more empirical or evaluation nature. Although included among the DSS they perform a more qualitative and informative task on disasters without providing an effective tool for the correct management of the emergency that makes them immediately usable as a support to the decision-maker in the phase of incipient danger or a few moments after the event. Thus, the broad review presented in the previous section has shown how the metadata, the management software (middleware), and sub-model analysis capable of interpreting data represent the cornerstones to work on in order to develop an innovative SDSS. It is, therefore, evident that institutions and agencies should be encouraged to use information technology, open-source software and open standards for EDM activities. It will result in a general system based on a geo-computerized environment that might be updated in real-time from different sources and which provides a central core of analysis that integrates the use of different solvers that collaborate - integrating, as foreseen in the objectives of the EU MUSTER Project [49].

\subsection{Computational models}

Play a crucial role in planning, and the development of simulation models is a significant challenge to grip with crisis management. Indeed those assist the decision-maker in drafting the appropriate plans; the use of DSS also allows you to plan not only the direct aspects but the evolution over time and the triggering of secondary phenomena not always directly related to the emergency. Upon it, a great gap is already represented by the limited possibility to directly evaluate the influence of heterogeneity into behaviours and the interference among different flows of people who operate different mode choices. It also emerged how dynamic assignment [50], and real-time applications [51], have been recently introduced and till now, the evolution over time has been extensively studied favouring a probabilistic approach. The introduction of the long and short-range sensors, floating car data, satellite and the VGI is giving impetus to a more straightforward definition of the problem. It follows that today a EDM must necessarily have a SDSS at its base, and the GIS component of the latter must be based on a rich and updated data package that is always kept active in the ordinary, and pre-disaster phases trough the creation of the spatial data infrastructures (SDI).

As a consequence of these statements, we can assume how the integration of ICT tools, and more generally ITS, allow public (e.g. municipalities, local administrations) and private (e.g. citizens) actors to increase their benefit while managing and using urban transport systems in emergency conditions. The information flow through mobile devices and web applications let the administrations increase the evacuees' consciousness and let them know what to do (e.g. which destination to reach, which path to undertake), modifying the way the evacuation will take place with respect to a scenario without ICT, and can be assumed that the introduction of such technologies will allow the decision-makers to shift the paradigm of the decisions undertaken by evacuees to a more sustainable system optimum (SO) model organized on cooperative behaviour, where evacuees interact with the system giving it back information upon behaviours and choices, letting the analyst monitor the demand and redefine information (i.e. suggested routes) according to the evolution of the emergency. 


\subsection{Collaborative system}

The possibility to organise a user-friendly app, as evaluated in Astarita et al. [52] will involve the citizens to support the project and become a source of crowd-sourced information. A suitably developed App can allow the evacuees, familiar or not (i.e. tourists) with the urban area, to receive through their smartphone information about the nature of the alert, the safe destination and the route. The quality of the system and user interface will be assessed via experimentation of the user requirements for a successful disaster management system architecture. The DSS server must be easy to use during the management of incoming information about the event. Its main function consists of storing the evacuees' spatial-time data during their route; this detection could be operated using individual mobile devices and transmitted to the SDSS itself. On the other side, the system's repository will also collect and store data from official sources. Collected data from the App will be used as a source for the statistical analysis between the forecasted and the experienced behaviour. Thus the foretasted destinations and routes that the SDSS provides to the users, whose position is unknown for the analyst and detected by the SDSS at the "Alert" time instant, and the experienced destinations and routes selected and undertaken by the group of users along the (road) network, will be analysed.

The comparison of the forecasted vs experienced data will be carried out utilizing statistical analysis in order to verify the capacity of the TSM to simulate destination and route choice during a "real" evacuation, and this further validation will be part of the process to help municipalities to draw up efficient planning solutions during different kind of emergencies.

\section{CONCLUSION}

The introduction of this new proposal will positively impact different fields, both technological and social.

Technological, the use of the proposed methodologies by public administration and citizens could allow the integration between available traffic data. Many data can be shared between ordinary traffic conditions and emerging conditions. In the specific, both off-line and online data, obtained by operating sensors (e.g. IoT), can be used. The use on the city can make advancement on the installed sensor network that can be beneficial from the use of other social groups, particularly voluntary associations and no-profit organizations.

The results in terms of prototypal DSS can suggest to different start-up enterprises to work in this field to produces advancement of SDSS more linked to the specific territory. Furthermore, it will introduce the possibility to gives the possibility to customize the DSS for each city, developing the model used and upgrading the quality of the information provided to citizens, maintaining the same App for all the cities where applied and then easy to read. A consisting upgrade resides into the possibility to divide the DSS from the other parts gives the opportunity to link it with the main system of traffic control. These models allow the construction of procedures to be included in hardware and software tools for advancement user information other than the current ones that give the forecasted path conditioned to a choice destination and sometimes to the conditions of the network in terms of flow and time. The data obtained by testing experiences are highly useful for the calculation of statistics and forecasting by means of regressive statistical models to better organize the functioning of systems for next emergencies. This new class of models, together with the availability of data in real-time, could in the future lead to new smart objects to support the evacuation towards different places: from simple open square to the main hospital.

Social, from the citizens perspective, the ICT system gives positive economic impacts to the community reducing risk and increasing social knowledge, with no additional costs 
(for technicians, public administrators, citizens. Moreover, the system will provide to public administration the possibility to organize several trials with the social associations, using the ICT system as reference managing. Furthermore, the proposal for a new SDSS, whose main characteristics consist in its modularity, interoperability among different sources and actors, capable of involving citizens to reduce social risks, is in line with the agenda of many public administration who have to reach the goals subscribed into the UN Agenda 2015 (isnerire citazione) in terms of sustainability, for a safe and inclusive environment that has to reduce the number of deaths and the number of people affected by losses during an emergency thus, to centre specific goals into the area of "disaster-resilient societies" and "Smart mobility".

Finally, the potentiality for the proposed SDSS can be resumed as: (i) public administration: Major and Civil Protection during evacuations; (ii) citizens: residents (e.g. workers, students), and tourists; (iii) planners: the DSS allows testing, according to a "whatif" approach, the evacuation plan; (iv) design technicians: civil, industrial, and information technicians can use a developed version of App-Web server and DSS; (v) national and regional Civil Protection: the results can be diffused at a national or regional level to let citizens use the same App, but with specific DSS for each area.

\section{REFERENCES}

[1] Peckham, R., Haastrup, P. \& Otway, H., A computer-based system for risk management support. Decision Support Systems, 4(4), pp. 481-489, 1988.

[2] Van Raemdonck, K., Macharis, C. \& Mairesse, O., Risk analysis system for the transport of hazardous materials. Journal of Safety Research, 45, pp. 55-63, 2013.

[3] Russo, F. \& Rindone, C., Urban exposure: Training activities and risk reduction. WIT Transactions on Ecology and the Environment, vol. 191, WIT Press: Southampton and Boston, pp. 991-1001, 2014.

[4] Di Gangi, M., Approaching the analysis of transport networks in emergency conditions for the design of evacuation plans. WIT Transactions on Ecology and the Environment, vol. 77, WIT Press: Southampton and Boston, 2004.

[5] Russo, F. \& Vitetta, A., Risk evaluation in a transportation system. International Journal of Sustainable Development and Planning, 1(2), pp. 170-191, 2006.

[6] Russo, F. \& Rindone, C., Safety of users in road evacuation: Planning internal processes and guidelines. WIT Transactions on the Built Environment, vol. 96, WIT Press: Southampton and Boston, 2007.

[7] Russo, F. \& Vitetta, A., Risk in anthropic environments: Methodologies for risk evaluation and exposition reduction. Environmental Health Risk III, 9, p. 31, 2005.

[8] Tavares, R.M., Evacuation processes versus evacuation models: "quo vadimus"? Fire Technology, 45(4), pp. 419-430, 2009.

[9] Russo, F. \& Chilà, G., Safety of users in road evacuation: RP vs. SP surveys in demand analysis. WIT Transactions on the Built Environment, vol. 101, WIT Press: Southampton and Boston, pp. 703-713, 2008.

[10] Russo, F. \& Rindone, C., Safety of users in road evacuation: The logical framework approach in evacuation planning. WIT Transactions on the Built Environment, vol. 101, WIT Press: Southampton and Boston, pp. 751-760, 2008.

[11] Wei, H., Zeng, Q.A., Hu, H., Wang, X. \& Kukreti, A.R., Integrated urban evacuation planning framework for responding to human-caused disasters over a surface transportation network. Transportation Research Record, 2041(1), pp. 29-37, 2008.

[12] Chen, X., Kwan, M.P., Li, Q. \& Chen, J., A model for evacuation risk assessment with consideration of pre- and post-disaster factors. Computers, Environment and Urban Systems, 36(3), pp. 207-217, 2012. 
[13] Chang, M.S., Tseng, Y.L. \& Chen, J.W., A scenario planning approach for the flood emergency logistics preparation problem under uncertainty. Transportation Research Part E: Logistics and Transportation Review, 43(6), pp. 737-754, 2007.

[14] Chakraborty, J., Tobin, G.A. \& Montz, B.E., Population evacuation: Assessing spatial variability in geophysical risk and social vulnerability to natural hazards. Natural Hazards Review, 6(1), pp. 23-33, 2005.

[15] Di Gangi, M., Safety of users in road evacuation: Modelling and DSS for pedestrian outflow. WIT Transactions on Ecology and the Environment, vol. 120, WIT Press: Southampton and Boston, pp. 497-508, 2009.

[16] Di Gangi, M., Watling, D. \& Di Salvo, R., Modeling evacuation risk using a stochastic process formulation of mesoscopic dynamic network loading. IEEE Transactions on Intelligent Transportation Systems, 2020.

[17] Vitetta, A., Musolino, G. \& Marcianò, F., Safety of users in road evacuation: Supply and demand-supply interaction models for users. WIT Transactions on the Built Environment, vol. 96, WIT Press: Southampton and Boston, 2007.

[18] Stathopoulos, A. \& Tsekeris, T., Economy of information in congested transport systems. IET Intelligent Transport Systems, 3(3), pp. 336-344, 2009.

[19] Di Gangi, M., Modeling evacuation of a transport system: Application of a multimodal mesoscopic dynamic traffic assignment model. IEEE Transactions on Intelligent Transportation Systems, 12(4), pp. 1157-1166, 2011.

[20] Marcianò, F.A., Musolino, G. \& Vitetta, A., Signal setting optimization on urban road transport networks: The case of emergency evacuation. Safety Science, 72, pp. 209-220, 2015.

[21] Russo, F. \& Chilà, G., Safety of users in road evacuation: Demand models. WIT Transactions on the Built Environment, vol. 96, WIT Press: Southampton and Boston, 2007.

[22] Russo, F. \& Chilà, G., Demand models in road evacuation: A synopsis of recent contributions. WIT Transactions on the Built Environment, vol. 116, WIT Press: Southampton and Boston, pp. 601-614, 2011.

[23] Mclean, M.A., Moeller, M. \& Desrosiers, A., Clear: A model for the calculation of evacuation-time estimates in emergency planning zones. Technical report, Pacific Northwest Lab., 1983.

[24] Di Gangi, M. \& Velonà, P., Safety of users in road evacuation: Pedestrian outflow models in a building. WIT Transactions on The Built Environment, vol. 96, WIT Press: Southampton and Boston, 2007.

[25] Sinuany-Stern, Z. \& Stern, E., Simulating the evacuation of a small city: The effects of traffic factors. Socio-Economic Planning Sciences, 27(2), pp. 97-108, 1993.

[26] Cova, T.J. \& Johnson, J.P., Microsimulation of neighborhood evacuations in the urbanwildland interface. Environment and Planning A, 34(12), pp. 2211-2229, 2002.

[27] Vitetta, A., Quattrone, A. \& Polimeni, A., Safety of users in road evacuation: Algorithms for path design of emergency vehicles. WIT Transactions on the Built Environment, vol. 101, WIT Press: Southampton and Boston, pp. 727-737, 2008.

[28] Gwynne, S., Galea, E., Owen, M., Lawrence, P.J. \& Filippidis, L., A review of the methodologies used in evacuation modelling. Fire and Materials, 23(6), pp. 383-388, 1999.

[29] Vorst, H.C., Evacuation models and disaster psychology. Procedia Engineering, 3, pp. $15-21,2010$.

[30] Santos, G. \& Aguirre, B.E., A critical review of emergency evacuation simulation models, 2004. 
[31] Pelechano, N. \& Malkawi, A., Evacuation simulation models: Challenges in modeling high rise building evacuation with cellular automata approaches. Automation in Construction, 17(4), pp. 377-385, 2008.

[32] Aguirre, B.E., El-Tawil, S., Best, E., Gill, K.B. \& Fedorov, V., Contributions of social science to agent-based models of building evacuation. Crowds in the 21st Century, Routledge, pp. 163-180, 2015.

[33] Kasereka, S., Kasoro, N., Kyamakya, K., Goufo, E.F.D., Chokki, A.P. \& Yengo, M.V., Agent-based modelling and simulation for evacuation of people from a building in case of fire. Procedia Computer Science, 130, pp. 10-17, 2018.

[34] Chilà, G., Musolino, G., Polimeni, A., Rindone, C., Russo, F. \& Vitetta, A., Transport models and intelligent transportation system to support urban evacuation planning process. IET Intelligent Transport Systems, 10(4), pp. 279-286, 2016.

[35] Gunes, A.E. \& Kovel, J.P., Using GIS in emergency management operations. Journal of Urban Planning and Development, 126(3), pp. 136-149, 2000.

[36] Wilson, R.D. \& Cales, B., Geographic information systems, evacuation planning and execution. Communications of the IIMA, 8(4), p. 2, 2008.

[37] Abdalla, R. \& Esmail, M., WebGIS for Disaster Management and Emergency Response, Springer, 2018.

[38] Sugumaran, V. \& Sugumaran, R., Web-based spatial decision support systems (webSDSS): Evolution, architecture, examples and challenges. Communications of the Association for Information Systems, 19(1), p. 40, 2007.

[39] Vizecky, K. \& El-Gayar, O., Increasing research relevance in DSS: Looking forward by reflecting on 40 years of progress. 2011 44th Hawaii International Conference on System Sciences, IEEE, pp. 1-9, 2011.

[40] Cova, T.J. \& Church, R.L., Modelling community evacuation vulnerability using GIS. International Journal of Geographical Information Science, 11(8), pp. 763-784, 1997.

[41] Russo, F. \& Chilà, G., Safety of users in road evacuation: Modelling and DSS for demand. WIT Transactions on Ecology and the Environment, vol. 120, WIT Press: Southampton and Boston, pp. 465-474, 2009.

[42] Zhou, L., Wu, X., Xu, Z. \& Fujita, H., Emergency decision making for natural disasters: An overview. International Journal of Disaster Risk Reduction, 27, pp. 567-576, 2018.

[43] Mileu, N. \& Queirós, M., Integrating risk assessment into spatial planning: Riskote decision support system. ISPRS International Journal of Geo-Information, 7(5), p. 184, 2018.

[44] Zhang, Z., Hu, H., Yin, D., Kashem, S., Li, R., Cai, H., Perkins, D. \& Wang, S., A cybergis-enabled multi-criteria spatial decision support system: A case study on flood emergency management. International Journal of Digital Earth, 12(11), pp. 1364$1381,2019$.

[45] Heinzlef, C., Becue, V. \& Serre, D., A spatial decision support system for enhancing resilience to floods: Bridging resilience modelling and geovisualization techniques. Natural Hazards and Earth System Sciences, 20(4), pp. 1049-1068, 2020.

[46] Zheng, X., Zhong, T. \& Liu, M., Modeling crowd evacuation of a building based on seven methodological approaches. Building and Environment, 44(3), pp. 437-445, 2009.

[47] Zhu, L., Song, W. \& Li, Q., Construction of emergency decision system based on GIS. 2009 Pacific-Asia Conference on Knowledge Engineering and Software Engineering, IEEE, pp. 171-174, 2009. 
[48] Olyazadeh, R., Aye, Z.C. \& Jaboyedoff, M., Development of a prototype for spatial decision support system in risk reduction based on open-source web-based platform. Conference Paper, 2013.

[49] Gadomski, A.M., Bologna, S., Costanzo, G.D., Perini, A. \& Schaerf, M., Towards intelligent decision support systems for emergency managers: The IDA approach. International Journal of Risk Assessment and Management, 2(3-4), pp. 224-242, 2001.

[50] Ayfadopoulou, G., Stamos, I., Mitsakis, E. \& Grau, J.M.S., Dynamic traffic assignment based evacuation planning for CBD areas. Procedia-social and Behavioral Sciences, 48, pp. 1078-1087, 2012.

[51] Blaschke, T. \& Schmidt, D., eMapBoard: From a collaborative situation mapping environment to a disaster management decision support system. InterCarto-InterGIS 12 Berlin, pp. 242-251, 2006.

[52] Astarita, V., Festa, D., Giofrè, G.P., Guido, G. \& Stefano, G., Mobile for emergencies m4em: A cooperative software tool for emergency management operations. Procedia Computer Science, 134, pp. 433-438, 2018. 